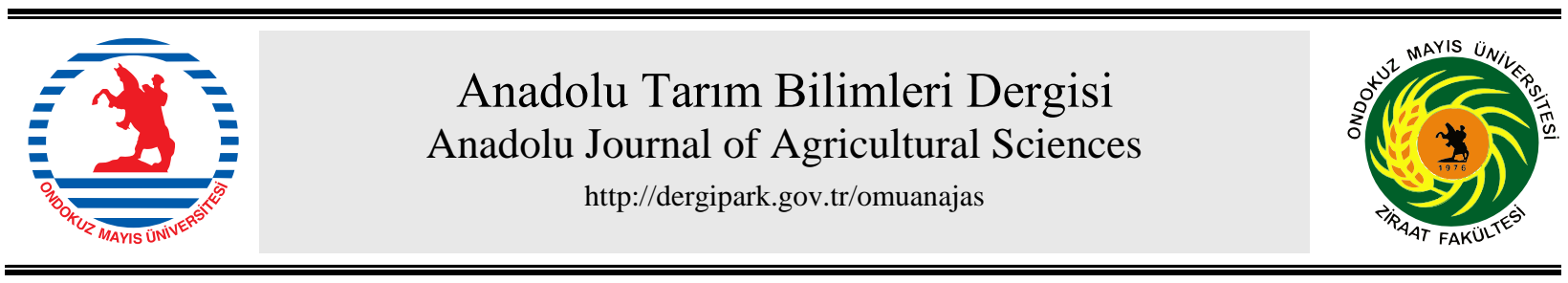

\title{
Araştırma/Research
}

Anadolu Tarım Bilim. Derg./Anadolu J Agr Sci, 36 (2021) ISSN: 1308-8750 (Print) 1308-8769 (Online) doi: 10.7161/omuanajas.845454

\section{Bazı Esansiyal Yağların Lucilia sericata Larvaları Üzerindeki Etkilerinin Belirlenmesi}

\author{
Meltem Kökdener ${ }^{*}$
}

Ondokuz Mayıs Üniversitesi, Sağllk Bilimleri Fakültesi, Sosyal Hizmet Bölümü, Samsun, Turkey

*Sorumlu yazar/corresponding author: kokdener@omu.edu.tr

Geliş/Received 23/12/2020～Kabul/Accepted 12/01/2021

\begin{abstract}
ÖZET
$\mathrm{Bu}$ çalışma dört farklı bitkiden elde edilen uçucu yağların Lucilia sericata' nın (Meigen, 1826) (Diptera: Calliphoridae) bazı biyolojik parameteleri üzerindeki etkilerini araștırmak üzere yapılmıştır. Araştırmada Mentha piperita L. (Lamiaceae), Piper nigrum L. (Piperaceae), Eugenia caryophyllata (Caryophyllaceae), Oleum pinus sp. elde edilen uçucu yağlarının 6 farklı konsantrasyonu (\%100, 60, 50, $40,30,20) \mathrm{L}$. sericata larvalarına uygulanmıştır. Denemeler laboratuvar şartlarında $(\% 70 \pm 0.2$ nem ve $24 \pm 0.5^{0} \mathrm{C}$ sıcaklık) yürütülmüştür. Bu çalışmada, artan uçucu yağ konsantrasyonları, larva ve pupa gelişim süresinde, pupa ve yetişkin ağırlığında, larva ve pupanın hayatta kalmasını etkilemiştir. Sonuçlar, tüm yağların $\% 100$ ve $\% 60$ konsantrasyonunun (çam turpentin hariç) öldürücü olduğunu göstermiştir. Bu, çalışmada kullanılan dört yağ içerisinde Piper nigrum'un L. sericata larvalarının kontrolünde diğer yağlardan daha etkili olduğu düşünülmektedir.
\end{abstract}

Determination of effects of some essential oil on Lucilia sericata larvae

\section{ABSTRACT}

This study was conducted to investigate the effects of essential oils obtained from four different plants on some biological parameters of Lucilia sericata (Meigen, 1826) (Diptera: Calliphoridae).Six different doses $((\% 100,60,50,40,30,20)$ of the essential oils obtained from Mentha piperita L. (Lamiaceae), Piper nigrum L. (Piperaceae), Eugenia caryophyllata (Caryophyllaceae), Oleum pinus sp. were applied to larvae of $L$. sericata in study. The experiments were carried out under laboratory conditions ( $70 \pm 0.2 \%$ humidity and $24 \pm 0.5^{\circ} \mathrm{C}$ temperature). In this study, increasing concentration of essential oil impacted to the larval and pupal development time, weight of pupae and adult, survival of larvae and pupae. The results showed that $100 \%$ and $60 \%$ concentration (except of pine turpentin) of all oil are lethal. Among the four oils used in the study, Piper nigrum is considered as more effective than other essential oil in the control of larvae of $L$. sericata.
Anahtar Sözcükler:

Esansiyel yağlar Lucilia sericata Larval gelişim Pupa ağırlığ1 Erişkin ağırlığı
Keywords: Essential oil Lucila sericata Larval development Pupal weight Adult weight

\section{Giriș}

Lucilia sericata (Meigen, 1826) (Diptera: Calliphoridae), tüm dünyada oldukça yaygın leş sineğidir. Aynı zamanda tıbbi, tarımsal ve veterinerlik bilimi açısından önemli kozmopolit bir türdür (Smith ve Wall, 1997; Singh ve ark., 2014; Greenberg, 1991; Byrd ve ark., 2010). Ölümden sonra cesede ilk gelen türlerden biri olması nedeniyle de (Taleb ve ark., 2018) adli soruşturmalarında ölüm sonrası geçen zamanın tahmininde (ÖSZ) sıklıkla 
kullanılmaktadır. L. sericata larvaları fakültatif ektoparazittir, hijyenik olmayan alanlar, mezbahalarda, kasaplarda, ahırlarda sıkça görülen bu sinekler mikobakteriyel enfeksiyon ajanlarının yayılmasına neden olmaktadır (Khater ve ark., 2009; 2011). Bu sinekler organik doku ile beslenirler ve sıklıkla hayvanlarda, insanlarda miyaza neden olurlar (Khater ve ark., 2009). Yumurtadan çıkan larvalar beslenirken, deride tahrişe neden olmaktadırlar (İlhan ve ark., 2018). Larvaların çıkardıkları enzimler ve ciltteki lezyon ve bu lezyonlarda oluşan toksik maddeler zamanla hayvanlarda, enfeksiyonlara, kaşıntı ve ölüme neden olurlar (Ütük, 2006; Khater ve ark., 2009; Aldemir ve ark., 2012).

Miyaz, koyunlarda süt ve yün üretiminin azalmasına, kilo ve doğurganlık sorunlarına (Snoep ve ark., 2002), cilt hasarına (Chabra ve Pathak, 2009) yol açmaktadır. Miyaz hayvancılık sektöründe (Hourigan, 1979) her yıl ciddi ekonomik kayıplara neden olmaktadır (Chhabra ve Pathak, 2009). İnsan sağlığı ve güvenliği için, miyaz hayvansal üretim endüstrisinde kontrol altına alınmalıdır, bu amaçla yapılacak ilk şeylerden biride buna neden olan sineklerle mücadeledir. L. sericata' nın kontrolü için tüm dünyada sentetik piretroid, organofosfat ve spreyler (Tellam ve Bowles, 1997) kullanılmaktadır. Pestisit bazlı kimyasal maddeler yaygın olarak sineklerle mücadelede kullanılmakta fakat bir süre sonra o maddeye karşı direnç gelişmesi nedeniyle etkisini yitirmektedirler (Whyard ve ark., 1994). Ayrıca bu kimyasal maddeler toprak ve suda kirliliğe, çevrede uzun süre bozulmadan kaldığ 1 için insan ve hayvan sağlığı üzerinde toksik etkilere neden olmaktadır (Hasheminia ve ark., 2011). Tüm dünya sineklerle mücadelede daha güvenilir, ekonomik ve çevresel sorunlara neden olmayan alternatif kimyasal madde bulma çabası içerisindedir (Isman, 2006). Bu amaçla kullanılan yöntemlerden biride bitkisel kaynaklı yağlardır. Uzun yıllardır antimikrobiyal, antifungal, antioksidan (Zhang ve ark., 2016), analjezik, antiseptik (Osanloo ve ark., 2018) ve anti-enflamatuar etkileri (Dogan ve Bagci., 2018; Asghari ve ark., 2018) nedeniyle tıpta veterinerlik alanında ve kozmetik sektöründe kullanılan bu uçucu yağların, son yıllarda böcek öldürücü etkileri dolayısıylada zırai mücadelede kullanılmaya başlanmıştır (Sengottayan 2013; Isman, 2006; Pavela, 2015; Regnault ve ark 2012). Bu esansiyel yağların, kısa sürede dekompoze olmaları, çevreye zarar vermemeleri, etkilerinin hızlı olaması, kullanım kolaylığı ve düşük maliyeteri nedeniyle zararlı mücadelesinde tercih edilmektedir (Isman, 2006; Shalaby ve ark., 2016). Bu uçucu yağlar eklembacaklıları uzaklaştırıcı, üremelerini ve gelişlerini engelleyici etkileri vardır (Papachristos ve Stamopoulos., 2002; Osman ve ark., 2016; Sharaby ve El-Nujiban, 2016).

İnsan ve hayvanlarda miyaza neden olan $L$. sericata larva ve erişkinlerine karşı çeşitli yağlarla ilgili çalışmalar yapılmışıtır (Morsy ve ark., 1998; Mazyad ve ark., 1999; El-Khateeb ve ark., 2003; Khater ve ark., 2009; 2011; 2018; Shalaby ve ark., 2016; Khater ve Geden., 2018), fakat bizim kullandığımız yağlar ve konsantrasyonlarıyla ilgili henüz hiç bir çalışmaya rastlanmamıştır. Bu çalışmada, Mentha piperita, Piper nigrum, Dianthus caryophyllus, Oleum pinus sp elde edilen yağların Lucilia sericata larvalarının bazı biyolojik özellikleri üzerindeki etkisinin araştırılması amaçlanmıştır.

\section{Materyal ve Yöntem}

\subsection{L. sericata Kolonisi}

Bu çalışmada kullanılan L. sericata erişkinleri 2017 yılında Samsun Ondokuz Mayıs Üniversitesi kampüsünden $\left(41^{\circ} 15^{\prime} \mathrm{N}, 36^{\circ} 19^{\prime} \mathrm{S}\right)$ toplanmış ve laboratuvar kolonisi oluşturulmuştur. L. sericata erişkinleri $(50 \mathrm{~cm}$ x $50 \mathrm{~cm}$ x 50 $\mathrm{cm}$ ) etrafi tülle çevrili kafeslerde, $24^{\circ} \mathrm{C}^{\prime}$ de, $\% 70 \pm 2$ bağ 1 nem ve $12: 12$ (A:K) foto periyot olan yetiştirme odalarında tutulmaktadır. Bu çalışma 2019 yılında Ondokuz Mayıs Üniversitesi Hayvan Fizyolojisi Araştırma Laboratuvarı' nda gerçekleştirilmiştir. Örnekler arasındaki genetik değişkenliği azaltmak için aynı koloniden alınan larvalar deneyde kullanılmıştır. Kafesteki erişkinler toz şeker ve su ile beslenmiştir. Kafeslerde yaklaşık 1:1 erkek ve dişi oranında 500 erişkin sinek bulunmaktadır. Sinek kolonilerfi 2 yıl boyunca korunmuş ve periyodik olarak vahşi erişkin yakalanarak desteklenmiştir. Yetişkin sineklerinin bulunduğu kafeslere $50 \mathrm{~g}$ taze tavuk karaciğeri içeren petri kapları yerleştirilerek yumurta elde edilmiştir. Çatlayan yumurtalardan elde edilen birinci evre larvalar hem sinek kolonisinin sürekli kültürü için hem de larvisidal deneyler için kullanılmıştır.

\subsection{Uçucu Yağlar}

Çalışmada kullanılan nane, karabiber, karanfil, çam terebentin esansiyel yağları bitki uzmanından elde edilmiştir. Çalışmada kullanılan dört uçucu yağın farklı dozları $(\% 20,30,40,50,60,100)$ saf su ve \%0,3'lük tween 80 (Emülgatör) kullanılarak hazırlanmıştır. Hazırlanan stok solüsyonlar kullanılanım anına kadar $4{ }^{\circ} \mathrm{C}^{\prime}$ de cam şişelerde saklanmıştır. 


\subsection{Biyolojik Çalışmalar}

Yumurtadan çıkan birinci evre (instar) larva grupları, ince bir fırça ile karıştırılmış, rastgele seçilen 15 adet birinci evre (instar) larva (L1) farklı konsantrasyonda uçucu yağ ile (1 $\mathrm{ml}$ solüsyonla) karıştırılmış $10 \mathrm{~g}$ tavuk karaciğeri içeren 200ml' lik plastik kaplara (Fıratmed Ürünleri, Fıratmed Ankara, Türkiye) konulmuştur. Her yağ konsantrasyonu için deneyler dört tekrar halinde gerçekleştirilmiştir. Kontrol olarak saf su kullanılmıştır. İçerisinde larva olan plastik kaplar inkübatöre aktarılmıştır (\%70 0.2 bağıl nem, 12:12 (A:K) foto periyotta ve $\left.24^{\circ} \mathrm{C}\right)$. Tüm kaplarda larvaların mortalitesi, ilk 12 saatten sonra etkisini göstermiştir. Ölü larvalar günde iki kere kontrol edilerek ortamdan çıkarılmıştır. Gözlemler yetişkin çıkıncaya kadar devam etmiştir. Yetişkin sinekler toplanarak $-20^{\circ} \mathrm{C}^{\prime}$ de tutulmuş, daha sonra dondurucudan çıkarılarak cinsiyet tayini yapılmıştır. Toplam larval mortalite (TLM): $\mathrm{TLM}=($ toplam ölü larva $\times 100) /$ test edilen toplam larva; Pupa oranı: Pupa $\%=\mathrm{A} / \mathrm{B} \times 100$ (burada: $\mathrm{A}=$ pupa sayıs1, $B=$ test edilen larva sayısı); erişkin sayıları ise: Erişkin sayısı $=\%=A / B \times 100$ (burada: $A=$ ortaya çıkan yetişkin sayısı, $\mathrm{B}=$ test edilen pupa sayısı denklemlerine göre hesaplanmıştır

\subsection{Istatistiksel Analiz}

Larva, pupal mortalite, pupa oranı, pupal ağırlık, erişkin cinsiyet oranı erişkin ağırlığı sinek erişkin ortaya çıkma oranları, tek yönlü varyans analiziyle incelenmiștir. Mortalite verileri, her bir konsantrasyon, kullanılan yağa göre ve bunlar arasındaki etkileşimler dikkate alınarak analiz edilmiştir. Aradaki farkın anlamlılığında ortalamalar Turkey HSD testi kullanılarak karşılaştırılmıştır. $\mathrm{F}$ değeri $\mathrm{p}<0.05$ olduğunda istatistiksel olarak anlamlı olduğu kabul edilmiştir. Esansiyel yağlarla biyolojik parametreler arasındaki ilişki lineer regresyon analiziyle incelenmiştir.

\section{Bulgular ve Tartışma}

Çok farklı alanlarda kullanılan ticari öneme sahip olan bitkisel yağların böcek öldürücü aktiviteleri son yıllarda tüm dünyanın dikkati çekmekte ve bu konuda yapılan araştırma sayısı gün geçtikçe artmaktadır. Bu çalışmada Mentha piperita L. (Lamiaceae), Piper nigrum L. (Piperaceae), Eugenia caryophyllata (Caryophyllaceae), Oleum pinus sp bitkilerinden elde edilen yağların, $L$. sericata larvalarının biyolojik parametreleri üzerindeki etkinliği araştırılmıştır. Larval, pupal süreler, larval, pupal mortalite, pupa ve erişkin ağırlıkları yağların tüm konsantrasyonlarında kontrolle karşılaştırılmıştır.

\subsection{Larval ve Pupal Gelişim Süresi}

Çalışmamızda yağların kimyasal yapısı ve konsantrasyonuna bağlı olarak da larval ve pupal sürelerin değiştiği görülmüştür (Çizelge 1). En uzun larval süre karabiber yağ $1 \% 20$ ' lik konsantrasyonlarda görülürken (11 gün) en kısa ise çam yağının tüm konsantrasyonları ve nane yağının \%20' lik konsantrasyonunda (6 gün) gözlemlenmiştir. Farklı yağlardaki larval gelişim zamanları karşılaştııılmış larval süreler arasındaki fark anlamlı çıkmıştır $(\% 20$ konsantrasyon için, $\mathrm{F}_{4,177}=7560.032$, $\mathrm{p}=0.000$; \%30 konsantrasyon için $\mathrm{F}_{3,109}=86.00,3 \mathrm{p}=0.000$; $\% 40$ konsantrasyon

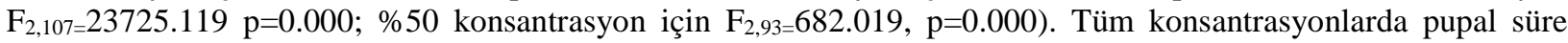
kontrole kıyasla daha uzundur. En kısa pupal süre karabiber yağ1 \%20' lik konsantrasyonlarda görülürken (7 gün) en uzun ise çam yağının tüm konsantrasyonları ve nane yağının \%20\% lik konsantrasyonunda (11 gün) gözlemlenmiştir. Farklı yağlardaki pupal gelişim süreleri arasındaki fark anlamlı çıkmıştır (\%20 konsantrasyon için, $\mathrm{F}_{4,177}=13691$,

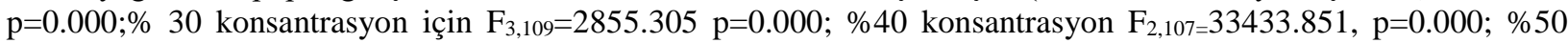
konsantrasyon için $\mathrm{F}_{2,93}=14961, \mathrm{p}=0.000$ ). Larval ve pupal süre ile yağ konsantrasyonları arasındaki istatistiksel açıdan anlamlı pozitif doğrusal bir ilişki vardır ( larval süre için; $R^{2}=0.90 ; P=0.0000$ pupal süre için $R^{2}=0.77$; $P=0.0000)$. Pinto ve ark. (2015), yaptıkları çalışmalarında Musca domestica Linnaeus 1758 (Diptera: Muscidae)' nın limon otu (Cymbopogon citratus) yağının konsantrasyonuna bağlı olarak gelişim süreleri farklı etkilenmiştir. Limon otunun $\% 5,10,25,100$ konsantrasyonlarıyla etkileşimlerinde gelişim sürelerinin uzadığ,$\% 50$ ve $\% 75$ konsantrasyonuyla etkileşimlerinde ise gelişim sürelerinin kısaldığı görülmüştür. Mukandiwa ve ark. (2012), yaptığı çalışmalarında Lucilia cuprina (Wiedemann, 1830) (Diptera: Calliphoridae) ve Chrysomya marginalis (Wiedemann, 1830) (Diptera: Calliphoridae), larvaların Alocasia zebrina, Clausena anisata, Erythina lysistemon ve Sparrmannia africana bitki ekstraklarıyla muamele edilince larval ve pupal gelişim sürelerinin uzadığını gözlemlenmişlerdir, bu bulguların sonuçları bizim çalışmamızın sonuçları ile uyumludur.

\subsection{Larval ve Pupal Mortalite Oranı}


Larva ve pupal mortalite oranları konsantrasyona ve yağın kimyasal yapısına göre farklılık göstermiştir. Yağların hepsinde $\% 100$ konsantrasyonda larval mortalite oranı $\% 100$ ' dür. Ayrıca $\% 60$ konsantrasyonda çam terebentin yağ 1 hariç larval mortalite oranı \%100' dür. Çizelge 2' de farklı yağ konsantrasyonlarındaki pupa ve erişkin sayıları verilmiştir. Yapılan çalışmada, en düşük larval mortalite oranı karanfil yağ $\% 20$ (\%6.6), en yüksek ise karabiber yağının \%20 ve karanfil \%30 konsantrasyonunda görülmüştür (\%33). Pupal mortalite yüzdesi en düşük \%20 çam terebentin yağında (\%0) en yüksek ise karanfil yağı \%30 konsantrasyonda görülür (\%50). Lineer regresyon analizi yağların tüm konsantrasyonları ile pupa sayıları ve erişkin sayıları arasında zayıf bir korelasyon olduğunu göstermiştir (pupa sayıları; $R^{2}=0$. 058; $P=0.0000$, erişkin sayıları; $R^{2}=0.091, P=0.0000$ ). Yaptığımız çalışmada yağların konsantrasyonları arttıkça mortalite oranları artmıştır. Kullanılan yağlar içerisinde karabiber yağ $L$. sericata larvaları üzerinde en etkili yağ olarak görülmüştür, bunu karanfil yağı ve nane yağı takip etmiştir. En az etkisi olan ise çam terebentin yağı bulunmuştur. Mohamed ve ark. (2016), yaptıkları çalışmalarında Commiphora molmol ve Balanites aegyptiaca bitki ekstraklarının yüksek konsantrasyonlarının L. sericata larvalarını tümüyle öldürdüğünü göstermişlerdir. Khater ve Khater, (2009) yaptıkları çalışmalarında \%16 konsantrasyonda çemen otu ve kereviz ekstraklarının $L$. sericata' nın pupa oranını ve yetişkin oranları oldukça azalttığını göstermiştir. Shalaby ve ark. (2016), yaptıkları çalışmalarında lavanta ve kâfur yağının \%32 lik konsantrasyonunda L. sericata'nın larval mortalite oranını \%100 ve \%93.3 olarak bulmuşlardır. Pinto ve ark. (2015) M. domestica ile yaptıkları çalışmalarıda kullanılan ekstrakların dozuna bağlı olarak mortalite oranının değiştiği bulmuşlardır ve bu bulgular bizim çalışmamızla uyumludur. Yaptığımız çalışmada en az pupa karanfil \%30, karabiber \%20 konsantrasyonda (10 pupa), en az erişkin karanfil \%30 konsantrasyonda görülmüştür (5 erişkin). Khater, (2017), L. sericata üzerinde Alianthus altissima, Anethum graveolens, Coriandrum sativum bitki ekstraklarının etkisini araştırdığı çalışmasında pupa oranlarının \%18-\%60 arasında erişkin çıkma oranının ise \%24.5-\%84.6 oranında değiştiği bulmuşlardır. Khater ve ark. (2011), L. sericata' üzerinde çemen otu, kereviz, turp ve hardal otu ekstraklarının etkisini araştırdıkları çalışmalarında pupa oranlarının, çemen ve kereviz ekstraklarının \%16 konsantrasyonunda belirgin bir şekilde azaldığını göstermiştir. Ayrıca hardal yağının \%8 konsantrasyonda, turp yağının \%12 konsantrasyonda, çemen ve kereviz yağının \%16 konsantrasyonda erişkin çıkmasının baskılandığını bildirilmiştir.

Çizelge 1. L. sericata’nın farklı konsantrasyondaki yağlarda larval ve pupa süreleri

Table 1. Larval and pupal duration of $L$. sericata in oils with different concentrations

\begin{tabular}{|c|c|c|c|}
\hline Konsantrasyon (\%) & $\overline{\text { Yağ }}$ & $\begin{array}{l}\text { Larval gelişim süresi } \\
\text { (gün) (ort } \pm \text { std) }\end{array}$ & $\begin{array}{lr}\begin{array}{l}\text { Pupal gelişim } \\
\text { (gün) }\end{array} \text { (ort } \pm \text { std) } & \\
\end{array}$ \\
\hline Kontrol & - & $8.02 \pm 0.08 b^{*}$ & $6.04 \pm 0.05 a$ \\
\hline \multirow[t]{4}{*}{20} & Karabiber & $11.03 \pm 0.06 \mathrm{c}$ & $7.03 \pm 0.06 \mathrm{a}$ \\
\hline & Karanfil & $6.09 \pm 0.02 \mathrm{a}$ & $10.02 \pm 0.08 \mathrm{~b}$ \\
\hline & Çam terebentin & $6.01 \pm 0.06 \mathrm{a}$ & $11.02 \pm 0.04 \mathrm{~b}$ \\
\hline & Nane & $6.01 \pm 0.06 a$ & $11.03 \pm 0.08 \mathrm{~b}$ \\
\hline Kontrol & - & $8.02 \pm 0.08 b$ & $6.04 \pm 0.05 \mathrm{a}$ \\
\hline \multirow[t]{4}{*}{30} & Karanfil & $8.18 \pm 0.09 b$ & $11.02 \pm 0.02 \mathrm{~b}$ \\
\hline & Çam terebentin & $6.02 \pm 0.07 \mathrm{a}$ & $11.01 \pm 0.053 b$ \\
\hline & Nane & $7.07 \pm 0.04 \mathrm{ab}$ & $11.01 \pm 0.06 b$ \\
\hline & Karabiber & - & - \\
\hline Kontrol & - & $8.02 \pm 0.08 b$ & $6.04 \pm 0.05 a$ \\
\hline \multirow[t]{4}{*}{40} & Çam terebentin & $6.05 \pm 0.01 \mathrm{a}$ & $11.05 \pm 0.01 \mathrm{~b}$ \\
\hline & Nane & $9.01 \pm 0.04 \mathrm{~b}$ & $10.03 \pm 0.06 \mathrm{~b}$ \\
\hline & Karanfil & - & - \\
\hline & Karabiber & - & - \\
\hline Kontrol & - & $8.02 \pm 0.08 b$ & $6.04 \pm 0.05 a$ \\
\hline \multirow[t]{4}{*}{50} & Çam terebentin & $6.11 \pm 0.05 a$ & $11.03 \pm 0.08 b$ \\
\hline & Nane & $9.02 \pm 0.06 b$ & $10.01 \pm 0.04 b$ \\
\hline & Karabiber & - & - \\
\hline & Karanfil & - & - \\
\hline Kontrol & - & $8.02 \pm 0.08 b$ & $6.04 \pm 0.05 a$ \\
\hline \multirow[t]{4}{*}{60} & Çam terebentin & $6.20 \pm 0.09 a$ & $11.03 \pm 0.07 \mathrm{~b}$ \\
\hline & Nane & - & - \\
\hline & Karabiber & - & - \\
\hline & Karanfil & - & - \\
\hline
\end{tabular}

* Aynı sütunda yer alan ve aynı harfle başlayan ortalamalar arasındaki farklılık Tukey-HSD testine göre istatistiksel olarak önemsizdir $(\mathrm{P}<0.05)$. (ort \pm std=Ortalama standart \pm sapma) 
Çizelge 2. L. sericata'nın farklı konsantrasyondaki yağlarda pupa ve erişkin sayıları

Table 2. Pupal and adult numbers of $L$. sericata in oils of different concentrations

\begin{tabular}{|c|c|c|c|c|c|}
\hline Konsantrasyon (\%) & Yă̆ & $\begin{array}{l}\text { Pupa } \\
\text { say1s1 (N) }\end{array}$ & $\begin{array}{l}\text { Pupa Sayis1 } \\
\text { (\%) }\end{array}$ & $\begin{array}{l}\text { Erişkin } \\
\text { sayısı (N) }\end{array}$ & $\begin{array}{l}\text { Erişkin } \\
\text { sayı1s1 (\%) }\end{array}$ \\
\hline Kontrol & - & 15 & 100 & 14 & 93 \\
\hline \multirow[t]{4}{*}{20} & Karabiber & 10 & 66 & 8 & 80 \\
\hline & Karanfil & 14 & 93 & 11 & 78 \\
\hline & Çam terebentin & 12 & 80 & 12 & 100 \\
\hline & Nane & 13 & 86 & 9 & 69 \\
\hline \multirow[t]{4}{*}{30} & Karanfil & 10 & 66 & 5 & 50 \\
\hline & Çam terebentin & 12 & 80 & 11 & 91 \\
\hline & Nane & 12 & 80 & 8 & 66 \\
\hline & Karabiber & - & - & - & - \\
\hline \multirow[t]{4}{*}{40} & Çam terebentin & 12 & 80 & 10 & 83 \\
\hline & Nane & 13 & 86 & 11 & 84 \\
\hline & Karanfil & - & - & - & - \\
\hline & Karabiber & - & - & - & - \\
\hline \multirow[t]{4}{*}{50} & Çam terebentin & 12 & 80 & 10 & 83 \\
\hline & Nane & 12 & 80 & 8 & 83 \\
\hline & Karanfil & - & - & - & - \\
\hline & Karabiber & - & - & - & - \\
\hline \multirow[t]{4}{*}{60} & Çam terebentin & 12 & 80 & 8 & 83 \\
\hline & Karanfil & - & - & - & - \\
\hline & Karabiber & - & - & - & - \\
\hline & Nane & - & - & - & - \\
\hline
\end{tabular}

(ort \pm std=Ortalama standart \pm sapma)

Çizelge 3. L. sericata'nın farklı konsantrasyondaki yağlarda pupa ve erişkin ağılıkları Table 3.Pupal and adult weights of $L$. sericata at different concentrations of oils

\begin{tabular}{|c|c|c|c|c|}
\hline $\begin{array}{l}\text { Konsantrasyon } \\
(\%)\end{array}$ & Yăg & $\begin{array}{l}\text { Pupa ağırlığ } 1 \\
\text { (mg) (ort } \pm \text { std) }\end{array}$ & $\begin{array}{l}\text { Erkek ağırlığ } 1 \\
\text { (mg) (ort } \pm \text { std) }\end{array}$ & $\begin{array}{l}\text { Dişi ağırlığ1 } \\
\text { (mg) (ort } \pm \text { std) }\end{array}$ \\
\hline Kontrol & - & $28.86 \pm 0.50 d^{*}$ & $27.95 \pm 0.10 \mathrm{~b}$ & $35.52 \pm 0.33 d$ \\
\hline \multirow[t]{4}{*}{20} & Karabiber & $19.60 \pm 0.47 \mathrm{a}$ & $30.09 \pm 0.58 c$ & $31.72 \pm 0.13 c$ \\
\hline & Karanfil & $19.23 \pm 0.50 \mathrm{a}$ & $28.16 \pm 0.71 \mathrm{~b}$ & $23.78 \pm 0.15 a$ \\
\hline & Çam terebentin & $23.23 \pm 0.32 \mathrm{c}$ & $28.61 \pm 0.17 \mathrm{~b}$ & $38.50 \pm 0.56 \mathrm{~d}$ \\
\hline & Nane & $21.32 \pm 0.20 \mathrm{~b}$ & $18.46 \pm 0.42 \mathrm{a}$ & $26.20 \pm 0.93 b$ \\
\hline Kontrol & - & $28.86 \pm 0.50 \mathrm{~d}$ & $27.95 \pm 0.10 \mathrm{c}$ & $35.52 \pm 0.33 d$ \\
\hline \multirow[t]{4}{*}{30} & Karanfil & $10.17 \pm 0.21 \mathrm{a}$ & $19.77 \pm 0.34 \mathrm{a}$ & $20.86 \pm 0.11 b$ \\
\hline & Çam terebentin & $23.02 \pm 0.34 \mathrm{c}$ & $25.50 \pm 0.15 b$ & $38.10 \pm 0.47 \mathrm{c}$ \\
\hline & Nane & $20.47 \pm 0.32 b$ & $28.28 \pm 0.81 \mathrm{c}$ & $18.40 \pm 0.78 \mathrm{a}$ \\
\hline & Karabiber & - & - & - \\
\hline Kontrol & - & $28.86 \pm 0.50 \mathrm{c}$ & $27.95 \pm 0.10 \mathrm{~b}$ & $35.52 \pm 0.33 a$ \\
\hline \multirow[t]{4}{*}{40} & Çam terebentin & $21.30 \pm 0.41 b$ & $21.70 \pm 0.16 \mathrm{a}$ & $35.80 \pm 0.84 a$ \\
\hline & Nane & $18.72 \pm 0.31 \mathrm{a}$ & $20.10 \pm 0.16 a$ & $35.36 \pm .0 .76 a$ \\
\hline & Karabiber & - & - & - \\
\hline & Karanfil & - & - & - \\
\hline
\end{tabular}




$\begin{array}{lllll}\text { Kontrol } & - & 28.86 \pm 0.50 \mathrm{c} & 27.95 \pm 0.10 \mathrm{c} & 35.52 \pm 0.33 \mathrm{c} \\ 50 & \text { Çam terebentin } & 19.77 \pm 0.39 \mathrm{~b} & 16.06 \pm 0.11 \mathrm{~b} & 32.43 \pm 0.95 \mathrm{~b} \\ & \text { Nane } & 14.36 \pm 0.42 \mathrm{a} & 14.25 \pm 0.13 \mathrm{a} & 12.21 \pm 0.16 \mathrm{a} \\ & \text { Karabiber } & - & - & - \\ & \text { Karanfil } & - & - & - \\ \text { Kontrol } & & & \\ 60 & - & 28.86 \pm 0.50 \mathrm{~b} & 27.95 \pm 0.10 \mathrm{a} & 35.52 \pm 0.33 \mathrm{~b} \\ & \text { Çam terebentin } & 18.80 \pm 0.36 \mathrm{a} & 28.47 \pm 0.53 \mathrm{a} & 18.51 \pm 0.14 \mathrm{a} \\ & \text { Karabiber } & - & - & - \\ & \text { Karanfil } & - & - & -\end{array}$

* Aynı sütunda yer alan ve aynı harfle başlayan ortalamalar arasındaki farklılık Tukey-HSD testine göre istatistiksel olarak önemsizdir $(\mathrm{P}<0.05)$. (ort \pm std=Ortalama standart \pm sapma).

\subsection{Pupa ve Erişkin A $\breve{g}$ ırlı̆̆}

Pupa ağırlığı ve erişkin ağırlığı yağların kimyasal yapısına ve konsantrasyonuna bağlı olarak değişmiştir. En ağır pupa çam terebentin yağında $\% 20$ ve \% 30 konsantrasyonda $(23.23 \pm 0.32 ; 23.02 \pm 0.34)$ en düşük ise karanfil yağı \%30 konsantrasyonda (10.17 \pm 0.21$)$ görülmüştür. Yağların pupal ağırlıkları arasındaki fark istatistiksel olarak

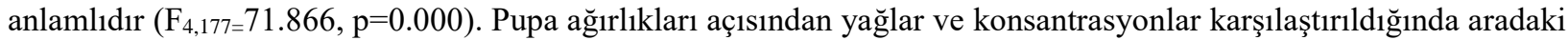
fark anlamlıdır $\left(\mathrm{F}_{4,177}=71.866 \mathrm{p}=0.000 ; \mathrm{F}_{3,109}=110.593, \mathrm{p}=0.000 ; \mathrm{F}_{2,107}=33.073, \mathrm{p}=0.000 ; \% 50\right.$ konsantrasyon için $\mathrm{F}_{2,93}=48.428, \mathrm{p}=0.000$ ). Lineer regresyon analizi yağların konsantrasyonları ile pupa ağırlıkları arasında bir korelasyon olduğunu göstermiştir $\left(R^{2}=0.042 ; P=0.000\right)$.

Çizelge 3' te farklı konsantrasyonlardaki yağlarda pupa ve erişkin ağırlıkları verilmiş̧ir. Dişi ve erkekler ağırlıkları, yağların konsantrasyonları açısından karşılaştırıldığında en ağır dişi çam terebentin yağı \%20 ve \%30 konsantrasyonda $(38.50 \pm 0.47 ; 38.14 \pm 0.56)$ en hafif dişi nane yağında \%50 konsantrasyonda $(12.21 \pm 0.16)$

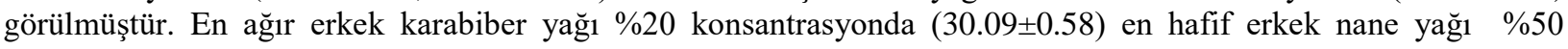
konsantrasyonda $(14.25 \pm 0.13)$ en hafif dişi nane yağ $1 \% 20$ konsantrasyonda görülmüştür. Yağların erişkin ağırlıkları arasındaki fark istatistiksel olarak anlamlıdır $\left(\mathrm{F}_{4,177}=71.866, \mathrm{p}=0.000\right)$.Dişi ağırlıkları yağların konsantrasyonları açısından karşılaştıııldığında $\% 20, \% 30$ ve \%50 konsantrasyonları için aradaki fark anlamlıyken (\%20 için: $F=18.954, p=0.000$; \%30 için: $F_{3,64}=47.871, p=0.000$; \%50 için: $\left.F_{2,50}=13.264, p=0.000\right) \% 40$ konsantrasyon için dişi ağırlıkları arasındaki fark anlamsızdır $\left(\% 40\right.$ için $\left.\mathrm{F}_{2,59}=0,021, \mathrm{p}=0.979\right)$. Erkek ağırlıkları yağların konsantrasyonları

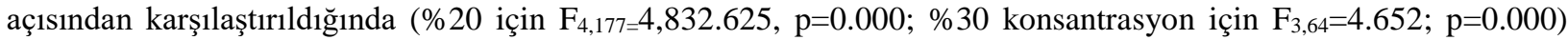
aradaki fark anlamlı; \%40 ve \%50 konsantrasyon için erkek ağırlıkları arasındaki fark anlamsızdır $\left(\mathrm{F}_{2,59}=3.497\right.$, $\mathrm{p}=0.039$; \%50 konsantrasyon için $\mathrm{F}_{2,50}=.004 \mathrm{p}=0.0966$ ). Lineer regresyon analizi yağların konsantrasyonları ile dişi ve erkek ağırlıkları arasında bir korelasyon olmadığını göstermiştir (dişi ağırlığı; $R^{2}=0$. 004; $P=0.0398$, erkek ağırlığ $\left.1 R^{2}=0.006, P=0.0911\right)$.

Bitkilerden elde edilen uçucu yağların sinek larvalarının kütikül yapısını deforme ettiği (Schmutterer ve ark., 2016) ve nöroendokrin kontrolüne etki ettiği bilinmektedir (Meurant ve ark., 1994). Larva büyüme, gelişme ve farklılaşma için gerekli olan nöro-hormonların salınmasından endokrin bezlerin sorumlu olduğu bilinmektedir (Akkol ve ark., 2020) dolayısıylada bu bezlerin çalışmasının etkilenmesi ve nörodejaneratif bozukluklara yol açmakta, larval gelişimi ve larval metabolizmayı etkilemektedir. Mohamed ve ark. (2016), yaptıkları çalışmalarında bitkisel yağlarların $L$. sericata larvalarını etkilemesi sonucunda küçük boyutlu ve deforme pupaların ve erişkinlerin oluştuğu görülmüştür. Khater ve ark. (2011), yaptı̆̆ çalışmada marul yağının larvada \%57, pupada \%50 ve yetişkinlerde $\% 50$ oranlarında deformiteye neden olduğunu göstermiş̧tir. Küçük, pigmentli ve bükülmüş, zayıf larvalara küçük, deformiteli pupa ve erişkinlere neden olmuştur, yaptığımız çalışmayla uyumludur.

\section{Sonuç}

Dört farklı bitki ekstraktlarını $L$. sericata larvalarının biyolojik parametreleri üzerindeki etkilerini incelediğimiz çalışmamızda sonucunda, Piper nigrumun dan elde edilen yağın $L$. sericata larvalarının kontrolünde diğer yağlardan daha etkili olduğu görülmüştür. Yüksek konsantrasyonlarda kullanıldıklarında larvaları öldüren morfolojik anormalliğe yol açan bu bitkisel yağlar kolaylıkla, yetişkinlerin ortaya çıkmasını önleyebilir. L. sericata' ya karşı sentetik böcek ilaçlarına alternatif olarak bitkisel yağların kullanılması hem ucuz hem de etkili bir yöntemdir. Elde ettiğimiz veriler ileride yapılması planlanan haşere önleme ve etkisiz hale getirmeye yönelik 
çalışmalarda böcek kontrol ajanlarının geliştirilmesine 1şık tutacaktır. Zararlılarla ve sineklerle mücadelede farklı esansiyel yağların toksik etkisini inceleyen çalışmalar planlanmalı, validasyon çalışmaları yapılmalı ve haşere yönetimi programlarına entegre edilmelidir.

\section{Kaynaklar}

Akkol, E. K., Ilhan, M., Kozan, E., Dereli, F.T.G. Sak, M., Sobarzo-Sánchez, E., 2020. Insecticidal Activity of Hyoscyamus niger L. on Lucilia sericata Causing Myiasis. Plants, 9(5): 655-665. doi :https://doi.org/10.3390/plants9050655.

Aldemir, O.S., Ural, K., 2012. Aysul, N., Derincegöz, O., Simsek, E., Güler, A.G. A case of traumatic myiasis in a dog. Türkiye Parazitoloji Dergisi, 36 (2): 109-11. doi:10.5152/tpd.2012.26.

Asghari, B., Zengin, G., Bahadori, M.B., Abbas, M.M., Dinparast, L., 2018. Amylase, glucosidase, tyrosinase and cholinesterases inhibitory, antioxidant effects and GC-MS analysis of wild mint (Mentha longifolia var. calliantha) essential oil: A natural remedy. European Journal of Integrati and Medicine, (22): 44-49. doi:10.1016/j.eujim.2018.08.004.

Byrd, J.H., Tomberlin, J.K., Castner, J.L., 2010. Insects of forensic importance. In: Byrd, J.H., Castner, J.L., (Eds).Forensic entomology: the utility of arthropods in legal investigations. CRC Press Boca Raton;. pp. 39-126.

Chhabra, M.B., Pathak, K.M.L., 2009. Myiasis of domestic animals and man in India. Journal of Veterinary Parasitology, 23 (1): 1-7.doi: 10.1007/s12639-012-0109-0.

Dogan, G., Bagci, E., 2018. Chemical composition of essential oil of Pinus nigra sub sp. Pallasiana (Pinaceae) Twigs, from different regions of Turkey. Journal of Essential Oil Bearing Plants, 21 (2): 511-519. doi:10.1080/0972060X.2017.1415771.

El-Khateeb, R.M., Abdel-Shafy, S., Zayed, A.A., 2003. Insecticidal effects of neem seed and vegetable oils on larval and pupal stages of sheep blowfly, Lucilia sericata (Diptera: Calliphoridae). Journal of the Egyptian Veterinary Medical Association, (63): 255-268.

Greenberg, B., 1991. Flies as forensic indicators. Journal of Medical Entomology, 28 (5): 565-577. doi: 10.1093/jmedent/28.5.565.

Hasheminia, S.M., Sendi, J.J., Jahromi, K.T., 2011. Moharramipour S. The effects of Artemisia annua L. and Achillea millefolium $L$. crude leaf extracts on the toxicity, development, feeding efficiency and chemical activities of small cabbage Pieris rapae L.(Lepidoptera: Pieridae). Pesticide Biochemistry and Physiology, 99 (3): 244-249. doi:10.1016/j.pestbp.2010.12.009.

Hourigan, J.W., 1979. Spread and detection of soroptic scabies of cattle in united states. Journal of American Veterinary Association, (175) 1278-1280.

Isman, M.B., 2006. Botanical insecticides, deterrents and repellents in modern agriculture and an increasingly regulated world. Annual Review of Entomology. (51): 45-66. doi:10.1146/annurev.ento.51.110104.151146.

Khater, H.F., 2009. The insecticidal activity of four medicinal plants against the blowfly Lucilia sericata (Diptera: Calliphoridae). International Journal of Dermatology, 48 (5): 492-497. doi: 10.1111/j.1365-4632.2009.03937.x.

Khater H.F., Hanafy, A.M., Abdel-Mageed, A.D,, Ramadan. M,Y., El-Madawy, R.S., 2011. The insecticidal effect of some Egyptian plant oils against Lucilia sericata (Diptera: Calliphoridae). International Journal of Dermatology, 50 (2): 187-194. doi: 10.1111/j.1365-4632.2009.03937.x.

Khater, K.S., 2017. Efficacy of some plant extracts on Lucilia Sericata (Meigen) (Diptera: Calliphoridae). Egyptian Academic Journal of Biological Sciences, Toxicology Pest Control, 9 (1): 1-7. doi:10.21608/eajbsf.2017.17047.

Khater, H.F., Ali, M.A., Abouelella,G.A., Marawan,M.A., Govindarajan, M., Murugan, K., Abbas, R.Z., Vaz, N.P., Benelli, G., 2018. Toxicity and growth inhibition potential of vetiver, cinnamon, and lavender essential oils and their blends against larvae of the sheep blowfly, Lucilia sericata. International Journal of Dermatology, 57: 449 - 457. doi: 10.1111/j.1365-4632.2009.03937.x.

Khater, H.F., Geden, C.J., 2018. Potential of essential oils to prevent fly strike and their effects on the longevity of adult Lucilia sericata. Journal of Vector Ecology, 43(2): 261-270. doi:10.1111/jvec.12310.

Mazyad, S.A., El-Serougi, A.O., Morsy, T.A., 1999. The efficacy of the volatile oils of three plants for controlling Lucilia sericata. Journal of the Egyptian Society of Parasitology, 29 (1): 91-100.

Meurant, K., Sernia, C., Rembold, H., 1994. The effects of azadirachtin a on the morphology of the ring complex of Lucilia cuprina (Wied) larvae (Diptera: Insecta). Cell and Tissue Research, 275 (2): 247-254. doi:10.1007/BF00319422.

Mohamed, H.S., Abbas, Fahmy, M.M., Attia, M.M., El Khateeb, R. M., Shalaby, H A., Massoud, A.M., 2016. The insecticidal activity of two medicinal plants (Commiphora molmol) and (Balanites aegyptiaca) against the 
blowfly Lucilia sericata (Diptera: Calliphoridae). International Journal of Advanced Research in Biological Sciences, 3(3): 144-158.

Morsy TA, Shoukry A, Mazyad SA, Makled KM. The effect of the volatile oils of Chenopodium ambrosioides and Thymus vulgaris against the larvae of Lucilia sericata (Meigen). Journal of the Egyptian Society of Parasitology, 1998; 28 (2): 503-510.

Mukandiwa, L., Eloff, J.N., Naidoo, V., 2012, Evaluation of plant species used traditionally to treat myiasis for activity on the survival and development of Lucilia cuprina and Chrysomya marginalis (Diptera: Calliphoridae). Veterinary Parasitology, 190 (3-4): 566-572. doi:10.1016/j.vetpar.2012.06.027.

Osanloo, M., Sedaghat, M.M., Esmaeili, F., Amani, A., 2018. Larvicidal activity of essential oil of Syzygium aromaticum (Clove) in comparison with its major constituent, eugenol, against Anopheles stephensi. Journal of Arthropod-Borne Diseases, 12 (4): 361-369.

Osman, S.E.I., Swidan, M.H., Kheirallah, D.A., Nour, F.E., 2016. Histological effects of essential oils, their monoterpenoids and insect growth regulators on midgut, integument of larvae and ovaries of Khapra beetle, Trogoderma granarium everts. Journal of Biological Science, (16): 93-101. doi:10.3923/jbs.2016.93.101.

Papachristos, D.P., Stamopoulos, D.C., 2002. Repellent, toxic and reproduction inhibitory effects of essential oil vapours on Acanthoscelides obtectus (Say) (Coleoptera: Bruchidae). Journal of Stored Products Research, 38 (2): 117-128. doi:10.1016/S0022-474X(01)00007-8.

Pavela, R., 2015. Essential oils for the development of eco-friendly mosquito larvicides: A review. Industrial Crops and Products, (76): 174-187. doi:10.1016/j.indcrop.2015.06.050.

Pinto, Z.T., Sánchez, F.F., Santos, A.R.D., Amaral, A.C.F., Ferreira, J.L.P., Escalona-Arranz, J.C., de Carvalho Queiroz, M.M., 2015. Chemical composition and insecticidal activity of Cymbopogon citratus essential oil from Cuba and Brazil against housefly. Revista Brasileira de Parasitologia Veterinária, 24 (1): 36-44. doi:10.1590/S1984-29612015006.

Regnault, R.C., Vincent, C., Arnason, J.T. 2012. Essential oils in insect control: Low-risk products in a highstakes world. Annual Review of Entomology, (57): 405-424. doi:10.1146/annurev-ento-120710-100554.

Schmutterer, H., 1990. Properties and potential of natural pesticides from the neem tree, Azadirachta indica. Annual Review of Entomology, 35 (1): 271-297. doi:10.1146/annurev.en.35.010190.001415.

Sengottayan, S.N., 2013. Physiological and biochemical effect of neem and other Meliaceae plants secondary metabolites against Lepidopteran insects. Frontiers in Physiology, (4): 359. doi:10.3389/fphys.2013.00359.

Shalaby, H.A., El Khateeb, R.M., El Namaky, A.H., Ashry, H.M., Kandil, O.M., El Dobal , S.K.A., 2016. Larvicidal activity of camphor and lavender oils against sheep blowfly, Lucilia sericata (Diptera: Calliphoridae). Journal of Parasitic Diseases, 40 (4): 1475-1482. doi:10.1007/s12639-015-0715-8.

Sharaby, A., El-Nujiban, A., 2016. Histological effects of some essential oils combination on different tissues of the black cutworm larvae Agrotis ipsilon (Hufn.). Journal of Innovations in Pharmaceutical and Biological Sciences, (3): 6-11.

Smith, K.E., Wall, R., 1997. Asymmetric competition between larvae of the blowflies Calliphora vicina and Lucilia sericata in carrion. Ecological Entomology, 22 (4): 468-474. doi: 10.1046/j.1365-2311.1997.00093.x.

Singh, B., Crippen, T.L., Zheng, L., Fields, A.T., Yu, Z., Ma, Q., Wood, T. K., Dowd, S.E., Flores, M., Tomberlin, J.K., Tarone, A.M.., 2015. A metagenomic assessment of the bacteria associated with Lucilia sericata and Lucilia cuprina (Diptera: Calliphoridae). Applied Microbiology and Biotechnology, 99(2):86983. doi 10.1007/s00253-014-6115-7.

Snoep, J.J., Sol, J., Sampimon, O.C., Roeters, N., Elbers, A.R.W., Scholten, H.W., Borgsteede, F.H.M., 2002. Myiasis in sheep in the netherlands. Veterinary Parasitology, 106 (4): 357-363. doi:10.1016/S03044017(02)00088-2.

Taleb, M., Açıkgöz, H.N., Tail, G., Djedouani. Bi, Toumi, M., 2018. Title first data on the distribution of Lucilia sericata meigen, Calliphora vicina Robineau Desvoidy and Chrysomya albiceps Wiedmann (Diptera: Calliphoridae) in Algeria title. Zoology and Ecology, 28 (2): 142-154. doi: 10.1080/21658005.2018.1462611.

Tellam, R.L., Bowles, V.M., 1997. Control of blowfly strike in sheep: Current strategies and future prospects. International Journal for Parasitology, 27 (3): 261-273. doi:10.1016/S0020-7519(96)00174-9.

Ütük, A.E., 2006. Bir köpekte travmatik myiasis olgusu. Fırat Üniversitesi Sağlık Bilimleri Dergisi, 20 (1): 9799.

Whyard, S., Downe, A.E.R., Walker, V.K., 1994. Isolation of an esterase conferring insecticide resistance in the mosquito Culex tarsalis. Insect Biochemistry and Molecular Biology, 24 (8): 819-827. doi:10.1016/09651748(94)90110-4.

Zhang, Y., Liu, X., Wang, Y., Jiang, P., Quek, S., 2016. Antibacterial activity and mechanism of cinnamon essential oil against Escherichia coli and Staphylococcus aureus. Food Control, (59): 282-289. doi:10.1016/j.foodcont.2015.05.032. 